\title{
Body size, sex and high philopatry influence the use of agricultural land by Galapagos giant tortoises
}

\author{
Kyana N. Pike, Stephen Blake, Freddy Cabrera \\ IAIN J. GORDON and Lin SCHWARZKOPF
}

\begin{abstract}
As agricultural areas expand, interactions between wild animals and farmland are increasing. Understanding the nature of such interactions is vital to inform the management of human-wildlife coexistence. We investigated patterns of space use of two Critically Endangered Galapagos tortoise species, Chelonoidis porteri and Chelonoidis donfaustoi, on privately owned and agricultural land (hereafter farms) on Santa Cruz Island, where a human-wildlife conflict is emerging. We used GPS data from 45 tortoises tracked for up to 9 years, and data on farm characteristics, to identify factors that influence tortoise movement and habitat use in the agricultural zone. Sixty-nine per cent of tagged tortoises used the agricultural zone, where they remained for a mean of 150 days before returning to the national park. Large male tortoises were more likely to use farms for longer periods than female and smaller individuals. Tortoises were philopatric (mean overlap of farmland visits $=88.7 \pm$ SE $2.9 \%$ ), on average visiting four farms and occupying a mean seasonal range of $2.9 \pm \mathrm{SE} 0.3$ ha. We discuss the characteristics of farm use by tortoises, and its implications for tortoise conservation and coexistence with people.
\end{abstract}

Keywords Agriculture, conservation, continuous time movement models, Galapagos giant tortoise, GPS tracking, habitat use, human-wildlife conflict, occurrence distribution

Supplementary material for this article is available at doi.org/10.1017/So030605320001167

KYANA N. PIKE (Corresponding author, (1) orcid.org/0000-0001-9259-2899) and Lin SchWARZkopf (10 orcid.org/0000-0002-1009-670X) College of Science and Engineering, James Cook University, 1 James Cook Drive, Douglas Townsville, QLD 4810, Australia. E-mail kyana.pike@my.jcu.edu.au

STePHEN BLAKE ${ }^{\star} \dagger$ Department of Biology, Saint Louis University, Saint Louis, USA

Freddy Cabrera Charles Darwin Foundation, Puerto Ayora, Santa Cruz, Galapagos, Ecuador

IAIN J. GoRDON $¥ \$$ (@) orcid.org/0000-0001-9704-0946) Central Queensland University, Townsville, Australia

${ }^{*}$ Also at: Wildcare Institute, Saint Louis Zoo, Saint Louis, USA

$\dagger$ Also at: Max Planck Institute for Animal Behaviour, Radolfzell, Germany

$\ddagger$ Also at: Fenner School of Environment and Society, The Australian National University, Canberra, Australia

\$Also at: James Hutton Institute, Craigiebuckler, Aberdeen, UK

Received 25 March 2020. Revision requested 4 June 2020.

Accepted 13 October 2020. First published online 8 July 2021.

\section{Introduction}

gricultural expansion is a major driver of land modifiA cation globally (Butler et al., 2007; Venter et al., 2016). As humans increase the geographical range of their activities, wild animals increasingly encounter human-modified areas (LaPoint et al., 2015; McClure et al., 2017). Agriculture typically expands into the most productive natural areas, which also provide important resources for wildlife, increasing the likelihood of negative human-wildlife interactions (Shackelford et al., 2015; Venter et al., 2016; Chopin et al., 2019). For example, migratory sandhill cranes Antigone canadensis tabida in North America congregate to overwinter in an area used increasingly for agriculture, which has led to crop use by the cranes and conflict with farmers (Boggie et al., 2018). In Africa, elephants Loxodonta africana move between foraging areas using paths that traverse land development and farms, leading to damage to crops and fences, and sometimes injury to people, livestock and elephants (Songhurst et al., 2016). Such overlap of space use by wildlife and people can result in human-wildlife conflicts (LaPoint et al., 2015; Panzacchi et al., 2016; Shaw, 2016).

Understanding factors driving the interactions between wildlife and agriculture is necessary to appropriately manage any conflicts (Cozzi et al., 2019). Some species interact with farms only in certain seasons, or at specific locations (Tyrrell et al., 2017), requiring different management actions from species that interact with agricultural areas year-round or in less predictable ways. Thus, management strategies are likely to be more effective if they are based on knowledge of temporal and spatial patterns of wildlife-agriculture interactions (Tyrrell et al., 2017; Cozzi et al., 2019). For instance, to mitigate the impact of migratory sandhill cranes (McIvor \& Conover, 1994; Boggie et al., 2018), farmers harvest grain before the cranes arrive, and supplementary food is provided for cranes on public land to attract them away from farms (Boggie et al., 2018). In Europe, information on the spatial extent of interactions between the wild boar Sus scro$f a$ and farms allowed researchers to evaluate the risk of crop predation for different farms, and to recommend ways to reduce crop damage in targeted areas, thereby reducing human-wildlife conflict (Cozzi et al., 2019).

On the Galapagos Islands, there is potential for humanwildlife conflict between Critically Endangered giant tortoises and farm owners (Blake et al., 2015b; Benitez-Capistros et al., 2016, 2018). On Santa Cruz Island, eastern Chelonoidis porteri and western Chelonoidis donfaustoi giant tortoises 
migrate from the lowlands to the highlands during the cool, dry season, following seasonal shifts in high quality food resources (Blake et al., 2013; Yackulic et al., 2017). Farming on Santa Cruz Island began in the early 1900 , and c. $88 \%$ of highland areas in the most productive part of the island have been converted for agriculture (Watson et al., 2010; Trueman et al., 2013). As a result, tortoises have few natural areas available to them in the highlands, and use farmland extensively (Blake et al., 2015a,b; Benitez-Capistros et al., 2018), foraging on a variety of native and introduced plant species, and sometimes on crops (Blake et al., 2015a,b). Tortoises occasionally destroy crop plants and break fences, potentially allowing livestock to escape. In addition, they may transmit pathogenic bacteria to livestock (Blake et al., 2015b; Cayot et al., 2017a,b; Benitez-Capistros et al., 2018; Nieto-Claudin et al., 2019). Although negative interactions between tortoises and farmers are rare, some land owners construct barriers or displace and harass tortoises to discourage them from returning (Benitez-Capistros et al., 2018).

No comprehensive evaluation of the spatial and temporal use of farmland by giant tortoises has been carried out on the Galapagos Islands (Blake et al., 2015b), although this information is important for the description, quantification and potential mitigation of this emergent conflict (CGREG, 2015; Guzmán \& Poma, 2015; Benitez-Capistros et al., 2018). Galapagos tortoises are keystone species that have suffered dramatic population declines caused by overexploitation, and their potential for recovery is hampered by invasive species and habitat loss (MacFarland et al., 1974; Blake et al., 2012; Gibbs et al., 2014). Balancing outcomes for famers and tortoises is, therefore, critical for the well-being of both people and wildlife.

The goals of our study were to: (1) quantitatively describe the spatio-temporal distribution of Galapagos tortoises in the agricultural zone of Santa Cruz Island, and (2) identify intrinsic and extrinsic factors that influence these patterns, to inform tortoise conservation and facilitate coexistence with people. We used existing data on the movement of tracked individuals of two species of giant tortoise: C. porteri, which occurs in the south-west of the island, and $C$. donfaustoi, which occurs in the east and south-east. The two species have only recently been recognized as genetically distinct (Poulakakis et al., 2015). They share many morphological and behavioural traits: both are partial seasonal migrants, and both use the agricultural zone (BastilleRousseau et al., 2016; Cayot et al., 2017a,b), but their ranges do not overlap. Therefore, to comprehensively investigate the use of agricultural land by tortoises, we included both species and the island's entire agricultural zone in our study. We addressed the following research questions and predictions: (1) Which factors influenced the duration of tortoise visits to the agricultural zone? As body size is correlated with the propensity to migrate into the highlands and

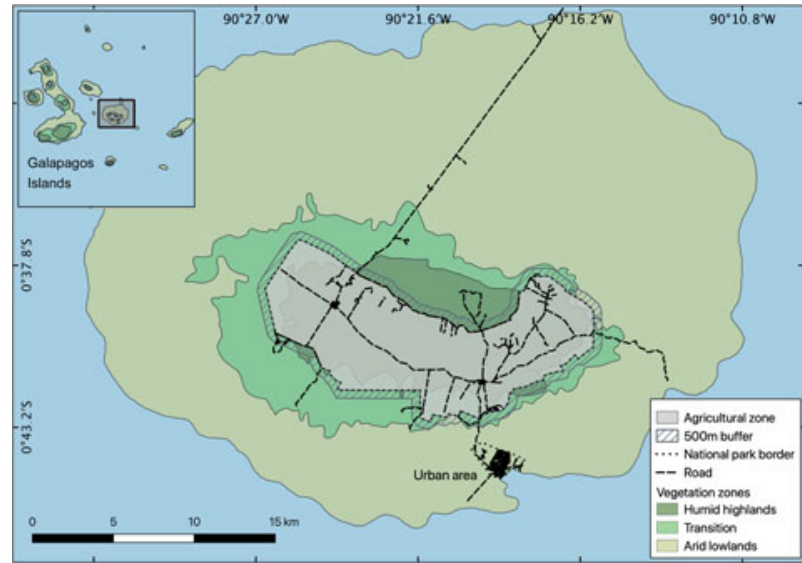

FIG. 1 Santa Cruz Island, with the national park, a small urban area, and the agricultural zone that covers most of the humid highlands.

the timing of migration, we predicted that larger individuals would remain in farmland for longer than smaller tortoises. (2) How did tortoises use space in the agricultural zone, and how many farms did they visit? Past analyses of migratory patterns suggested that some tortoises travelled long distances in the agricultural zone (Blake et al., 2012; Yackulic et al., 2017), thus we expected that individual tortoises would use several farms. (3) What was the extent of interannual philopatry within the agricultural zone? High levels of philopatry have been reported for other tortoise species (Bernstein et al., 2007; Lee et al., 2007), so we expected that these tortoises would revisit the same areas for multiple years.

\section{Study area}

The $986 \mathrm{~km}^{2}$ Santa Cruz Island is an extinct volcano in the centre of the Galapagos Archipelago, $926 \mathrm{~km}$ off the coast of Ecuador. It rises to $860 \mathrm{~m}$ altitude and has three distinct vegetation zones (Fig. 1) that are influenced by local and annual weather patterns. There is a hot, wet season during January-May, and a cool, dry season during JuneDecember (Trueman \& D'Ozouville, 2010). Arid lowlands are dominated by cacti and deciduous vegetation, and are most productive during the wet season (McMullen, 1999; Rivas-Torres et al., 2018). Palo santo Bursera graveolens woodland occurs in the transition zone to the cooler, wetter climate of the humid highlands, which are more consistently productive throughout the year (McMullen, 1999; Trueman et al., 2013). The natural vegetation of the humid highlands consists of Scalesia spp. forest at lower elevations, with ferns, sedges, grasses and Miconia species dominating as humidity increases. However, most of this zone is now dominated by various introduced and invasive species (Jaramillo Díaz \& Guèzou, 2011; Blake et al., 2012; Laso et al., 2020). These vegetation zones have shaped tortoise migrations over the 
centuries (Yackulic et al., 2017). As the dry season approaches and the forage quality declines in the lowlands, the tortoises migrate to the highlands until the wet season returns. As agriculture expands in the highlands of Santa Cruz, tortoises increasingly encounter human-modified areas (Blake et al., 2013; Yackulic et al., 2017).

Land use on the island is in two broad categories: c. $12 \%$ is privately owned land (11.6\% agricultural land and $0.4 \%$ urban area), and $88 \%$ is a national park managed by the Galapagos National Park Directorate (Fig. 1). The private land includes most of the highland area, which is used predominately for agriculture, and the urban settlement of Puerto Ayora in the lowlands. In the agricultural zone, land is used mostly for livestock grazing (42\%) and crops (43\%). The remainder (15\%) is used for private dwellings or tourism, or is abandoned land (CGREG, 2015; BenitezCapistros et al., 2018). As most of the land encountered by tortoises is, or has been, used for some form of agriculture, hereafter we refer to all private properties in the highland area as farms.

\section{Methods}

\section{GPS tracking of tortoises}

We collected data on tortoise movements during 2009-2018 on Santa Cruz Island. Twenty-seven tortoises of the western C. porteri (10 male, 17 female) and 18 individuals of the eastern C. donfaustoi (9 male, 9 female) species were fitted with GPS tracking devices (e-obs GmbH, Munich, Germany), following the animal handling procedures of the Galapagos National Park and the Max Planck Institute of Animal Behaviour (Blake et al., 2013). The majority of the GPS units were programmed to record locations hourly during 5.00-19.00 as tortoises are largely immobile at night, but some $(15 \%)$ recorded locations at finer time scales or 12 -hour intervals. Not all tortoises could be tracked in concurrent seasons because of tag failure; individual tortoises were tracked for a mean of 1,313 \pm SE 139 days (range 102-2,936 days).

All tortoise location data used in this study are freely available online from Movebank (Wikelski et al., 2019). We combined the GPS locations of tortoises with spatial data on the extent of farms collected by the Galapagos Government Council in 2014 (CGREG, 2015). To assess how often tortoises migrated to the highlands, but did not access farms, we included tortoise movements within a $500 \mathrm{~m}$ buffer around the agricultural zone, which extended into the national park (Fig. 1). To determine the duration of tortoise visits and their use of space in the agricultural zone, we used QGIS 2.18.23 (QGIS Development Team, 2016) to extract all locations of all tortoises that visited farms (31 tortoises during 2009-2018). Because tortoises were tracked continuously, but typically only used the highlands periodically, we created subsets of the GPS locations for each period that a tortoise used the agricultural zone. We defined a farmland visit as the time spent by a tortoise in the agricultural zone, from the first date of their presence within the $500 \mathrm{~m}$ buffer around the farms to the date they exited this area (113 unique farmland visits for 31 individual tortoises).

\section{Factors influencing the duration of tortoise visits to the agricultural zone}

To determine the factors influencing the duration of farmland visits, we used linear mixed models, constructed with the lme4 1.1.23 package (Bates et al., 2014) in $R$ 4.0.2 (R Core Team, 2020). As tortoises visited farms on multiple occasions, all mixed models included individual tortoise identity as a random effect, to account for effects of repeat observations of the same individual (Grueber et al., 2011). We used the number of days per farmland visit (with a square root transformation to meet model assumptions) as the response variable and examined the effects of sex, size (curved carapace length), species and month of entry and exit as explanatory variables. Tortoises that arrived later in the cool, dry season might have visited farms for shorter periods than tortoises that arrived earlier in the dry season, because once the wet season begins, tortoises tend to migrate back to the lowlands. Therefore, to assess if there was a relationship between the time tortoises remained in the agricultural zone and the month they entered or exited, we included these in the model as fixed effects.

\section{Space use by tortoises in the agricultural zone}

To describe individual tortoise movement patterns in the agricultural zone, we first categorized movement strategies from continuous time movement models using the $\mathrm{ctmm}$ 0.5.6 package in $R$ (Calabrese et al., 2016). We selected this approach because it allows the user to incorporate telemetry error into model-fitting, which enables confidence intervals for model estimates. It also allows the user to select the appropriate movement model (e.g. Brownian motion, Ornstein-Uhlenbeck, or independent identically distributed) for their data, to produce accurate and precise interpolations of an animal's trajectory and space use, especially with respect to any biases resulting from spatial autocorrelations (Fleming et al., 2014, 2016). We used these models to estimate the occurrence distributions of tortoises, using time-series kriging to evaluate the number of farms visited, and how intensively individual tortoises used the farms. We excluded four tortoises with only one farmland visit as we could not examine philopatry. In addition, we excluded tortoises with farmland visits with too few locations to create a reliable estimate for their occurrence distribution, either 
because tortoises were in the highlands for too few days ( $\mathrm{n}=17$ farmland visits), or were on a 12-hour tracking cycle ( $\mathrm{n}=4$ tortoises and 10 farmland visits). The data filtering process produced a subset of 23 tortoises $(C$. donfausto : two females and six males; $C$. porteri: seven females and eight males) that made a total of 83 farmland visits. We checked tortoise locations for outliers attributed to equipment error (such as implausible locations) using the outlie function from the $\mathrm{ctmm}$ package in $R$ (Calabrese et al., 2016). We then generated a variogram that incorporated telemetry error (GPS satellite dilution of precision) for each farmland visit for each tortoise, which we then used to seed the movement model fitting process using the $\mathrm{ctmm}$. fit function with a perturbative hybrid restricted maximum likelihood (pHREML) optimizer to account for farmland visits with a small sample size. The ctmm.fit process estimated which movement model best characterized the animal's movement process and their movement parameters, based on their relocation data (Calabrese et al., 2016; Fleming \& Calabrese, 2017). We then used these underlying movement models to create an occurrence distribution estimate for 83 farmland visits for each of the 23 tortoises, to extract the $25,50,75,95$ and $99 \%$ utilization distribution contours.

All occurrence distribution estimates were exported as shapefiles using the rgdal 1.4-4 package in $R$ (Bivand et al., 2019). We performed an intersect analysis, in QGIS, to quantify the number of farms within each occurrence distribution polygon that contained the maximum likelihood 25, 50, 75, 95 and $99 \%$ utilization distribution contours. We also calculated the area enclosed by each contour in each farm to assess the proportion of farmland used by tortoises.

\section{Inter-annual philopatry within the agricultural zone}

We calculated the degree of spatial overlap among farmland visits for each individual tortoise using the overlap function in the $\mathrm{ctmm}$ package. The overlap function uses Bhattacharyya coefficients to compare the similarity between the tortoise's fitted continuous time movement models, with greater similarity indicating high fidelity to the same areas (Winner et al., 2018).

\section{Model selection}

For linear mixed models we used Akaike's information criterion (AIC) to assess model fit, prioritizing models with the smallest AIC value explaining the most variance (Burnham \& Anderson, 2002). To assess which model had the most explanatory power, we used model averaging, by establishing a top set of models that were within at least five AIC values of the top model. Using the AICmodavg package (Mazerolle, 2015), only models in the top set that had confidence intervals that did not include zero were considered reliable predictors (Symonds \& Moussalli, 2011).

\section{Results}

Of the 45 tortoises tracked, 31 (69\%) migrated to the agricultural zone. We found females were less likely to visit the agricultural zone than males. Just over half $(54 \%)$ of the tagged females migrated to the agricultural zone compared to $89 \%$ of tagged males. Only one tortoise (a C. porteri female) migrated from the lowlands into the $500 \mathrm{~m}$ buffer around the agricultural zone but did not enter farmland during the study period, however, she did so in other years. Thirteen of the 31 tracked tortoises remained in the agricultural zone for $>6$ months (22\% of all farmland visits), longer than the entire cool, dry season, and five tortoises remained for $>1$ year ( $6 \%$ of all farmland visits). Female tortoises most often entered farmland in October $38 \%$ of 53 farmland visits by females) and usually left in February ( $35 \%$ of 53 visits), whereas males most often entered in August (25\% of 60 farmland visits by males) and left in January ( $28 \%$ of 60 visits). Mean duration of farmland visits was $150 \pm$ SE 11 days (range $2-765$ days).

Factors influencing the duration of tortoise visits to the agricultural zone

Tortoise body size (curved carapace length) was the strongest predictor of the duration of farmland visits, followed by sex (Table 1, Fig. 2). We found that larger male and female tortoises tended to spend longer in the agricultural zone, with the largest males staying for the longest periods of time. Males remained in the agricultural zone for a mean of $181 \pm$ SE 6 days, compared to $116 \pm$ SE 9 days for females. There was no significant effect of species, or the month of entry or exit, on the duration of farmland visits (Supplementary Table 1).

\section{Space use by tortoises in the agricultural zone}

Tortoise movements on farms were best described by the Ornstein-Uhlenbeck-F motion anisotropic model (fitted with telemetry error), indicating that movements were characterized by sporadic foraging periods within a range centred around a location (Fleming et al., 2014, 2016). The OrnsteinUhlenbeck-F model showed that individuals walked a mean distance of $550 \mathrm{~m}$ per day (95\% CI 520-579 m), and showed directional persistence for c. 1 hour $\left(58 \mathrm{~min}, 95 \%\right.$ CI $48.4^{-}$ $73.2 \mathrm{~min}$ ). Tortoises varied in their intensity of use of different farms (Fig. 3), using a mean of $4 \pm$ SE 0.5 farms (range 1-24) within their $99 \%$ utilization distributions, but showed concentrated use of $2 \pm$ SE 0.14 farms (range 1-7) within their $25 \%$ utilization distributions per farmland visit 
TABLE 1 Top variables identified by generalized linear mixed models for factors influencing the duration of tortoise visits to the agricultural zone. The analysis is based on 113 farmland visits by 31 tagged tortoises that were tracked in the agricultural zone during 2009-2018. For each model, the table shows the Akaike information criterion (AIC) value, the difference from the AIC score of the best model ( $\triangle$ AIC), AIC weight from model averaging, the model estimate and standard error for the models in the top set, and $95 \%$ confidence intervals.

\begin{tabular}{llllll}
\hline Model & AIC & $\Delta$ AIC & AIC weight & Estimate \pm SE & $95 \%$ CI \\
\hline Curved carapace length & 654.86 & 0.00 & 0.82 & $0.071 \pm 0.021$ & $0.029,0.116$ \\
Sex & 658.11 & 3.25 & 0.16 & $10.194 \pm 0.590$ & $8.936,11.428$ \\
Female & & & & $2.332 \pm 0.810$ & $0.641,4.071$ \\
Male & & & 0.02 & \\
Null & 662.75 & 7.88 & & & \\
\hline
\end{tabular}

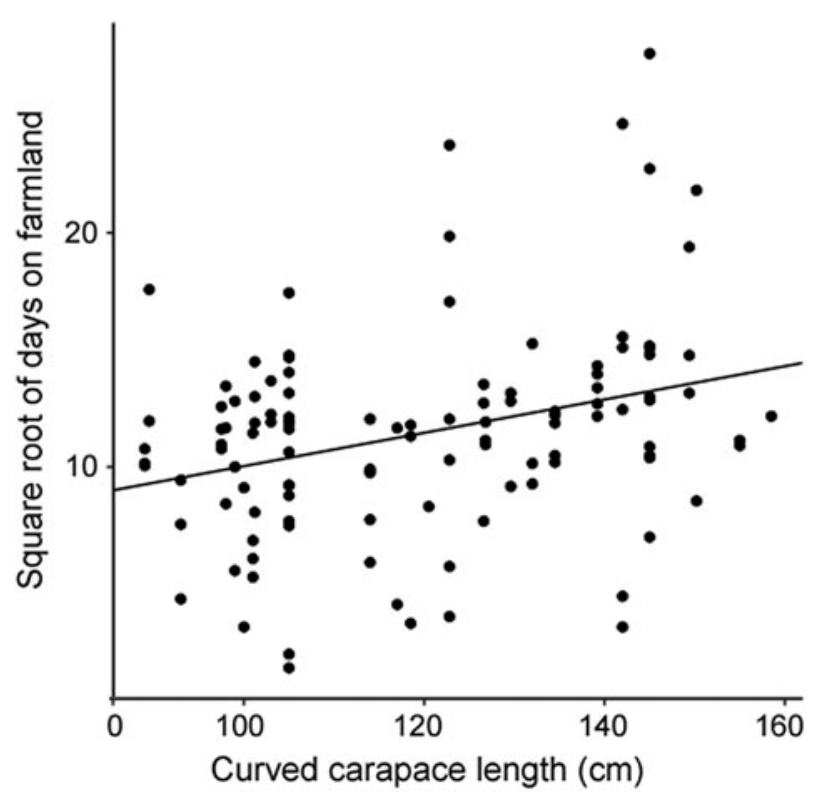

FIG. 2 The relationship between the number of days spent on farms per farmland visit and the size (curved carapace length) of the individual tortoise. Data were taken from 113 farmland visits by 31 Galapagos giant tortoises (Chelonoidis porteri and Chelonoidis donfaustoi) tracked in the agricultural zone during 2009-2018. The trendline is from the best fit model from Table 1.

(Supplementary Table 2). During a farmland visit, tortoises used a mean of $2.9 \pm \mathrm{SE} 0.29$ ha. This was on average $<10 \%$ of the total area of a farm, and $<1 \%$ of the farm was likely to be used intensely for activities such as foraging or resting (indicated by the $25 \%$ contour; Supplementary Table 2).

\section{Inter-annual philopatry within the agricultural zone}

Individual tortoises showed a high degree of spatial overlap of their farmland visits among years (Supplementary Table 3). Overlap data were highly skewed (skewness $=-2.24$ ) towards $>80 \%$ overlap, indicating most tortoises had a strong affinity for the same areas across farmland visits (Fig. 4). Tortoises showed consistently high philopatry over many years (i.e. overlap was high for farmland visits irrespective of the time interval between visits).

\section{Discussion}

Our main goal was to describe the spatial and temporal distribution of tortoise use of the agricultural zone of Santa Cruz Island, Galapagos, and to identify factors that influenced tortoise movement. We found that the agricultural zone was generally accessible to tortoises, as there was only one occasion when an individual migrated to the highlands but remained outside farmland, although the same individual entered farmland in other years. Tortoises intensively use small areas within multiple farms for prolonged periods during the cool, dry season for c. 5 months. Tortoises showed strong philopatry in space use within farms over multiple years. We found no evidence of speciesspecific differences in the duration of farmland visits.

Factors influencing the duration of tortoise visits to the agricultural zone

Tortoise size and sex influenced the length of stay on farmland. Larger tortoises tended to spend the most time on farms, probably because they migrate into the highlands earlier than smaller individuals, to satisfy their higher absolute metabolic demands and food requirements (Yackulic et al., 2017; Bastille-Rousseau et al., 2018). Although larger individuals generally spent more time in the agricultural zone, large males tended to spend more time than large females. Unlike males, females are constrained to delay their migrations to the highlands until they have nested (Blake et al., 2013). Farmers can expect that large individuals will be the first to arrive in the cool, dry season, and that smaller individuals will arrive later, but most tortoises leave farmlands at approximately the same time, regardless of sex or body size (Yackulic et al., 2017).

The extensive time tortoises spend in the agricultural zone indicates it is an important resource. Different land uses and crops could provoke conflict at different times of the year. For example, during the cool, dry season when forage quantity in the national park is low, tortoises congregate in the agricultural zone and compete with cattle for grass. There is some evidence that the presence of tortoises may increase the productivity of vegetation on Galapagos 


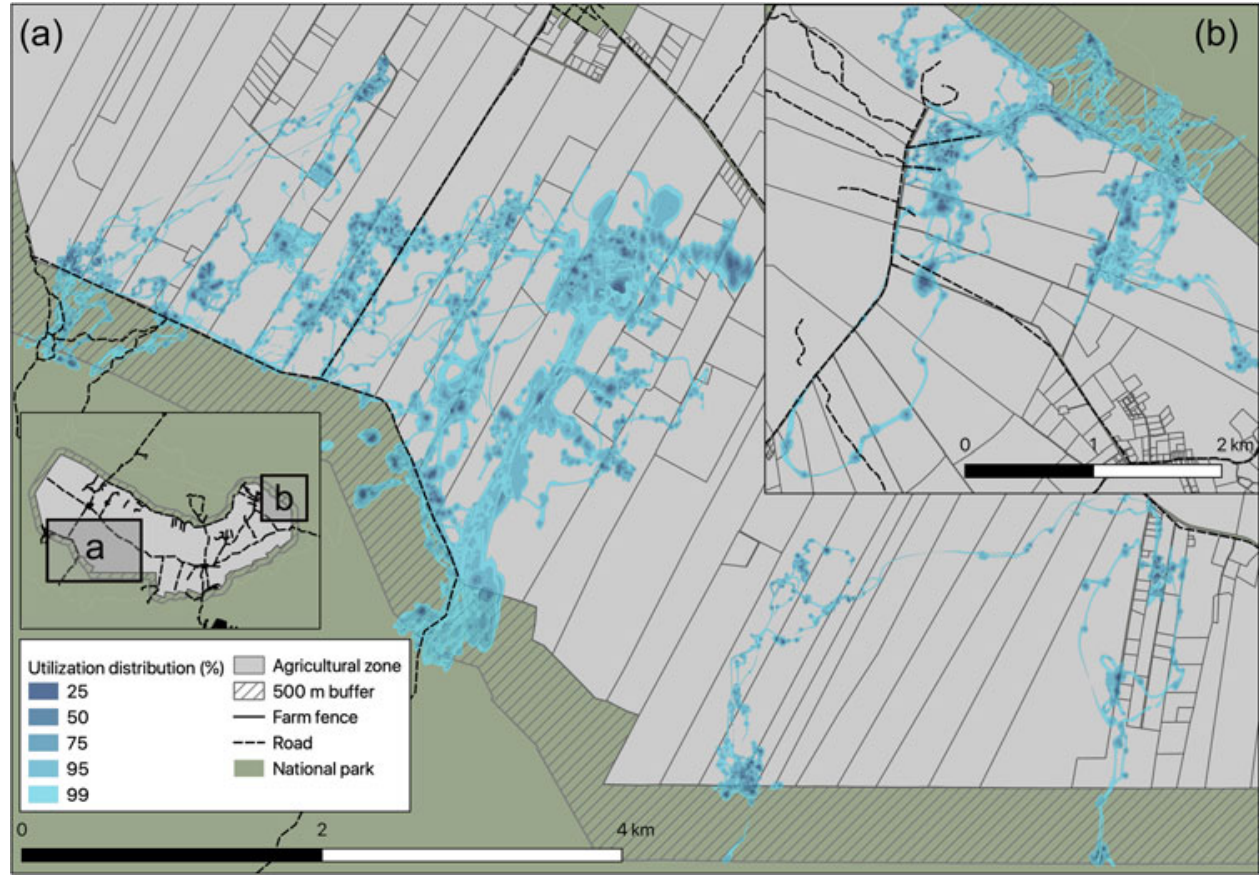

FIG. 3 Use of farmland by tortoises in the agricultural area of Santa Cruz Island. Data were taken from 23 tortoises tracked during 2009-2018: (a) 14 individuals of $C$. porteri and (b) 9 individuals of $C$. donfaustoi. The shaded areas show the $25-99 \%$ maximum likelihood utilization distribution; darker shades indicate higher intensity of use.
(Bastille-Rousseau et al., 2017), and grazing herbivores often increase grass sward productivity if rainfall is high (Milchunas \& Lauenroth, 1993; Augustine \& McNaughton, 2006). However, prolonged drought conditions during the dry season can reduce grass productivity, which can result in poor body condition and death of cattle (SB \& FC, pers. obs.). Under such conditions, competition with the more resilient tortoises may have considerable impacts on cattle farmers.

Unlike cattle production, fruit and vegetable production on Galapagos increases during the hot, wet season, when tortoises use the agricultural zone less. We found, however, that a substantial percentage of farmland visits (22\%) were for an extended period of time, and overlap of tortoises and fruits and vegetable crops could lead to increasing conflict. Currently, we do not have adequate data on where these crops are grown in relation to tortoise activity, which will be important for any future conflict mitigation. Such information could be used for zonal planning that minimizes spatio-temporal overlap between tortoises and crops.

Another potential problem associated with tortoises spending longer periods in the agricultural zone is the risk of exchange of pathogens, including bacteria that are resistant to antimicrobial treatments, between wild tortoises and livestock. In a sample of faeces of C. porteri, $100 \%$ contained microbes with resistance genes, making tortoises that use farmland a likely reservoir for resistant strains (Nieto-Claudin et al., 2019). Pathogen transmission between wildlife and livestock is a negative consequence of wildlife interactions with agriculture and could pose a risk to tortoises, livestock and human health in the Galapagos islands (Gordon, 2018; Nieto-Claudin et al., 2019).
Tortoises may remain longer on farms (beyond the months predicted based on a bioenergetics model by Yackulic et al., 2017) for several reasons. Firstly, food plants with high nutritional value, such as crops and introduced grasses and herbs used for cattle forage, are now a dominant component of tortoise diets in the agricultural zone (Blake et al., 2015a). These plants may fulfil the tortoises' energy requirements, reducing their need to migrate into the lowlands for the wet season. Secondly, many farmers maintain artificial ponds on their farms, typically for watering cattle (CGREG, 2015), although ponds are also created specifically to attract tortoises for tourism. Tortoises are attracted to water bodies, and prior to conversion of land for agriculture, they would have mostly encountered ephemeral ponds in the highlands (Froyd et al., 2014). As with other wildlife species, the availability of multiple artificial freshwater ponds throughout the year might encourage tortoises to remain on farms longer than predicted from energy requirements alone. Thirdly, fences may restrict tortoise movement, as they do for other wildlife (Jakes et al., 2018). Tortoises may struggle to find their way off a fenced farm and thus remain on a farm for longer. However, during our study, we only saw one such example involving a tagged tortoise, and many farms remain relatively permeable for tortoises (the authors, unpubl. data).

\section{Space use by tortoises in the agricultural zone}

Most tortoises used 1-4 farms, primarily during the cool, dry season, but one tortoise used 24 farms in a single visit. The proportion of each farm used by an individual tortoise is 


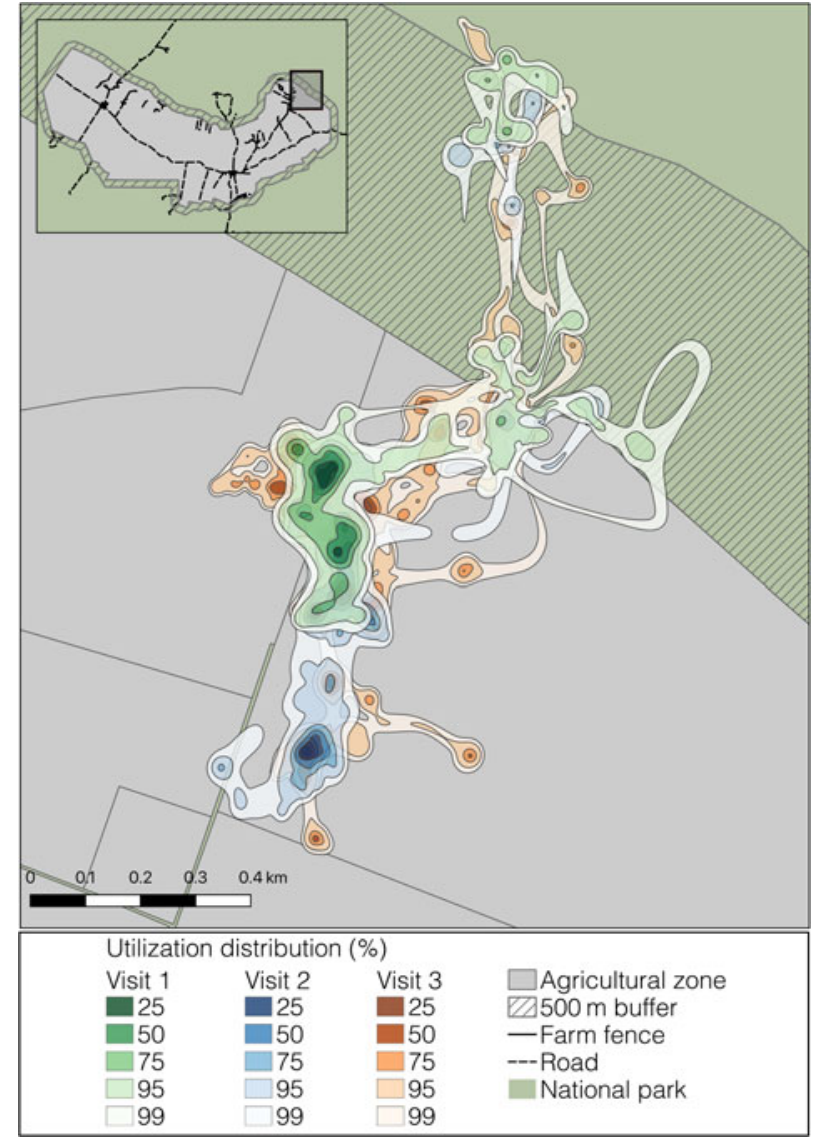

FIG. 4 Occurrence distributions of one eastern Santa Cruz tortoise C. donfaustoi during three separate farmland visits in the agricultural zone. The shaded areas show the $25-99 \%$ utilization distribution; darker shades indicate higher intensity of use. There is much spatial overlap of utilization between farmland visits, indicating high inter-annual philopatry within the agricultural zone.

relatively small $(<8 \%$ of the area of an average farm; Supplementary Table 2), most of which is used with low intensity (e.g. for transit). Although at present tortoises generally use only a small proportion of farmland, tourism and the local population are expected to increase, and this could exacerbate negative interactions between farmers and tortoises (Sampedro et al., 2018). Local demand for beef and pork is also expected to increase, as Galapagos prohibits the import of these products (CGREG, 2015; Sampedro et al., 2018). Given that the agricultural zone cannot expand further, farmers will need to increase livestock densities on existing land to meet demand, and could be less tolerant of tortoises sharing forage with cattle, especially if forage quality continues to decline. We also found tortoise distribution on farmland was clustered, and the temporary sedentary ranges of individual tortoises overlapped extensively. This probably reflects variation in resource availability within farms (e.g. ponds, high-quality forage areas and shade), but fine-scale data on resource distribution are needed to quantify the influence of different resources on tortoise distribution. If the resources that tortoises use most frequently can be identified, land-use plans could be established at the level of individual farms, to enable physical separation of critical resources for tortoises from production areas.

Our estimates for the number of farms visited by tortoises are probably conservative. Our information on the location, extent and type of farm was based on the Galapagos Government Council's census conducted in 2014, and our data include tortoise movements beyond 2014, up to 2018 . During this time, mean farm size has probably decreased, as land holders subdivide and sell land for residential development, or divide farms among family members. Land holders with smaller farms are more likely to report damage caused by tortoises, and to build barriers or harass and displace tortoises (Benitez-Capistros et al., 2018). In addition, because tortoises routinely use multiple farms, and this number is probably higher than our estimates, conservation strategies in the agricultural zone will require consultation and collaboration with a large, and increasing, number of landowners. Developing strategies on the management of mobile wildlife species, such as tortoises, on private land should involve all stakeholders.

\section{Inter-annual philopatry within the agricultural zone}

We found that, over 9 years, tortoises had a consistently high degree of spatial overlap among farmland visits, i.e. the same tortoises often re-used the same farms and the same areas on inter-annual visits, consistent with the observation that individuals tended to use the same migratory paths over years (Bastille-Rousseau et al., 2018). Philopatry has been documented in a variety of tortoises and turtles (e.g. Bernstein et al., 2007; Lee et al., 2007). Consistently revisiting the same areas may indicate that tortoises use cognitive spatial maps to access important resources. For example, elephants and primates remember the location and distribution of important fine-scale resources, such as waterholes or fruiting trees, and use their cognitive spatial maps to guide long-distance movements to access these areas (Polansky et al., 2015; Hopkins, 2016). Research with captive giant tortoises has demonstrated their long-term memory and cognitive abilities (Gutnick et al., 2020). Tortoises may use cognition and memory to find resources, and measures encouraging them to use areas where they do not damage fences or crops may be remembered and effective across multiple seasons.

\section{Conclusion}

We investigated the temporal and spatial patterns of farmland use by Galapagos tortoises, described the extent of the 
interaction, and identified the size of areas and the average number of landholders affected by wildlife movements. Our data suggest tortoises repeatedly use relatively small areas; this may facilitate land-use planning for tortoise conservation at the scale of individual farms. However, some tortoises moved across multiple farms, and the development of conservation strategies could involve large numbers of landowners. For Galapagos, a globally significant biodiversity hotspot, we recommend prioritizing further research to determine: (1) the socio-economic and land-use trajectory of the agricultural zone across space and time, (2) the ecological requirements of giant tortoises that are met by farms, and the nature and scale of emergent negative interactions with people, and (3) strategies that can be used at different scales to enable sustainable coexistence of tortoises and people on inhabited islands. The situation we observed in Galapagos is an example of increasingly common wildlife-agriculture interactions. Our study demonstrates that knowledge of wildlife movement and space use on farms can be used to describe and quantify wildlife-farmland interactions, and how such data could contribute to improving strategies to manage human-wildlife interactions.

Acknowledgements We thank the Galapagos National Park Directorate for permission to conduct this study; the Ministry of Agriculture for their collaboration; the Charles Darwin Foundation for their collaboration and support; the owners of Finca Mariposa, Rancho Primicias, Rancho El Chato 2, Finca Montemar and Pikaia Lodge for allowing us access to their land; Sharon Deem, Ainoa Nieto Claudin, José Haro and Fredy Villamar for technical and logistical support in the field and comments on this text; and two anonymous reviewers for their critiques. This research was supported by the Winifred Violet Scott Charitable Trust and a Prestige Research Training Program awarded to KNP, the National Science Foundation (DEB 1258062), the Max Planck Institute for Animal Behaviour (Radolfzell, Germany), the National Geographic Society (CRE grant No. WWW-048R-17 awarded to $\mathrm{SB}$ ), e-obs GMBH, the Saint Louis Zoo Institute for Conservation Medicine, the Galapagos Conservation Trust, The Houston Zoo, the Woodspring Trust, the Swiss Friends of Galapagos and the British Chelonian Group. This publication is contribution number 2316 of the Charles Darwin Foundation for the Galapagos Islands.

Authors contributions Conceptualization: KNP, SB, IJG, LS; data collection: SB, FC; data analysis: KNP; writing: KNP; revision and editing: $S B, I J G, L S$.

\section{Conflicts of interest None.}

Ethical standards Animal handling procedures followed research permit PC-36-17 of the Galapagos National Park, and this research otherwise abided by the Oryx guidelines on ethical standards.

\section{References}

Augustine, D.J. \& McNaughton, S.J. (2006) Interactive effects of ungulate herbivores, soil fertility, and variable rainfall on ecosystem processes in a semi-arid savanna. Ecosystems, 9, 1242-1256.
Bastille-Rousseau, G., Potts, J.R., Yackulic, C.B., Frair, J.L., Ellington, E.H. \& Blake, S. (2016) Flexible characterization of animal movement pattern using net squared displacement and a latent state model. Movement Ecology, 4, 15.

Bastille-Rousseau, G., Gibbs, J.P., Campbell, K., Yackulic, C.B. \& BLAKE, S. (2017) Ecosystem implications of conserving endemic versus eradicating introduced large herbivores in the Galapagos Archipelago. Biological Conservation, 209, 1-10.

Bastille-Rousseau, G., Yackulic, C., Gibbs, J., Frair, J., Cabrera, F. \& Blake, S. (2018) Migration triggers in a large herbivore: Galapagos giant tortoises navigating resource gradients on volcanoes. Ecology, 100, e02658.

Bates, D., Mächler, M., Bolker, B. \& Walker, S. (2014) Fitting Linear Mixed-Effects Models Using lme4. arxiv.org/abs/1406.5823 [accessed 1 February 2021].

Benitez-Capistros, F., Hugé, J., Dahdouh-Guebas, F. \& Koedam, N. (2016) Exploring conservation discourses in the Galapagos Islands: a case study of the Galapagos giant tortoises. Ambio, 45, 706-724.

Benitez-Capistros, F., Camperio, G., Hugé, J., Dahdouh-Guebas, F. \& Koedam, N. (2018) Emergent conservation conflicts in the Galapagos islands: human-giant tortoise interactions in the rural area of Santa Cruz island. PLOS ONE, 13, e0202268.

Bernstein, N.P., Richtsmeier, R.J., Black, R.W. \& Montgomery, B.R. (2007) Home range and philopatry in the ornate box turtle, Terrapene ornata ornata, in Iowa. The American Midland Naturalist, 157, 162-174.

Bivand, R., Keitt, T. \& Rowlingson, B. (2019) rgdal: Bindings for the 'Geospatial' Data Abstraction Library. R package version 1.4-8. CRAN.R-project.org/package $=$ rgdal [accessed 1 February 2021].

Blake, S., Wikelski, M., Cabrera, F., Guezou, A., Silva, M., SAdeghayobi, E. et al. (2012) Seed dispersal by Galapagos tortoises. Journal of Biogeography, 39, 1961-1972.

Blake, S., Yackulic, C.B., Cabrera, F., Tapia, W., Gibbs, J.P., Kummeth, F. \& Wikelski, M. (2013) Vegetation dynamics drive segregation by body size in Galapagos tortoises migrating across altitudinal gradients. Journal of Animal Ecology, 82, 310-321.

Blake, S., Guezou, A., Deem, S., Yackulic, C. \& Cabrera, F. (2015a) The dominance of introduced plant species in the diets of migratory Galapagos tortoises increases with elevation on a human-occupied Island. Biotropica, 47, 246-258.

Blake, S., Yackulic, C., Wikelski, M., Tapia, W., Gibbs, J., Deem, S. et al. (2015b) Migration by Galapagos Giant Tortoises Requires Landscape-Scale Conservation Efforts. Galapagos Report 2013-2014, 144-150. Galapagos National Park Directorate, Governing Council of Galapagos, Charles Darwin Foundation \& Galapagos Conservancy, Puerto Ayora, Galapagos, Ecuador.

Boggie, M.A., Carleton, S.A., Collins, D.P., Vradenburg, J. \& SROKA, C.J. (2018) Using stable isotopes to estimate reliance on agricultural food subsidies and migration timing for a migratory bird. Ecosphere, 9, e02083.

Burnham, K. \& Anderson, D. (2002) Model Selection and Multi-Model Inference: A Practical Information-Theoretic Approach. and edition. Springer, Secaucus, USA.

Butler, S.J., Vickery, J.A. \& Norris, K. (2007) Farmland biodiversity and the footprint of agriculture. Science, 315, 381-384.

Calabrese, J.M., Fleming, C.H. \& Gurarie, E. (2016) Ctmm: an $R$ package for analyzing animal relocation data as a continuous-time stochastic process. Methods in Ecology and Evolution, 7, 1124-1132.

Cayot, L.J., Gibis, J.P., Tapia, W. \& Caccone, A. (2017a) Chelonoidis donfaustoi. In The IUCN Red List of Threatened Species 2017: e.T90377132A90377135. dx.doi.org/10.2305/IUCN.UK.2017-3. RLTS.T90377132A90377135.en [accessed 13 August 2018]. 
Cayot, L.J., Gibbs, J.P., Tapia, W.H. \& Caccone, A. (2017b) Chelonoidis porteri. In The IUCN Red List of Threatened Species 2017: e.T9026A82777132. dx.doi.org/10.2305/IUCN.UK.2017-3.RLTS. T9026A82777132.en [accessed 1 February 2021].

Consejo de Gobierno del Régimen Especial de Galápagos (CGREG) (2015) Censo de Unidades de Producción Agropecuaria de Galápagos 2014 (UPA). In Consejo de Gobierno del Régimen Especial de Galápagos (CGREG) p. 1-143. Galapagos, Ecuador.

Chopin, P., Bergkvist, G. \& Hossard, L. (2019) Modelling biodiversity change in agricultural landscape scenarios - A review and prospects for future research. Biological Conservation, 235, 1-17.

Cozzi, M., Prete, C., Viccaro, M. \& Romano, S. (2019) Impacts of wildlife on agriculture: a spatial-based analysis and economic assessment for reducing damage. Natural Resources Research, $28,15-29$.

Fleming, C.H. \& Calabrese, J.M. (2017) A new kernel density estimator for accurate home-range and species-range area estimation. Methods in Ecology and Evolution, 8, 571-579.

Fleming, C.H., Calabrese, J.M., Mueller, T., Olson, K.A., Leimgruber, P. \& Fagan, W.F. (2014) From fine-scale foraging to home ranges: a semivariance approach to identifying movement modes across spatiotemporal scales. The American Naturalist, 183, E154-E167.

Fleming, C.H., Fagan, W.F., Mueller, T., Olson, K.A., Leimgruber, P. \& Calabrese, J.M. (2016) Estimating where and how animals travel: an optimal framework for path reconstruction from autocorrelated tracking data. Ecology, 97, 2562-2569.

Froyd, C.A., Coffey, E.E.D., van der KnaA, W.O., van Leeuwen, J.F.N., Tye, A. \& Willis, K.J. (2014) The ecological consequences of megafaunal loss: giant tortoises and wetland biodiversity. Ecology Letters, 17, 144-154.

Gibbs, J.P., Hunter, E.A., Shoemaker, K.T., Tapia, W.H. \& Cayot, L.J. (2014) Demographic outcomes and ecosystem implications of giant tortoise reintroduction to Espanola Island, Galapagos. PLOS ONE, 9, e114048.

Gordon, I.J. (2018) Review: Livestock production increasingly influences wildlife across the globe. Animal, 12, s372-s382.

Grueber, C.E., Nakagawa, S., Laws, R.J. \& Jamieson, I.G. (2011) Multimodel inference in ecology and evolution: challenges and solutions. Journal of Evolutionary Biology, 24, 699-711.

Gutnick, T., Weissenbacher, A. \& Kuba, M.J. (2020) The underestimated giants: operant conditioning, visual discrimination and long-term memory in giant tortoises. Animal Cognition, 23, 159-167.

Guzmán, J.C. \& Poma, J.E. (2015) Bioagriculture: An Opportunity for Island Good Living. Galapagos Report 2013-2014, pp. 25-29. Galapagos Report 2013-2014, Galapagos National Park Directorate, Governing Council of Galapagos, Charles Darwin Foundation \& Galapagos Conservancy, Puerto Ayora, Galapagos, Ecuador.

Hopkins, M.E. (2016) Mantled howler monkey spatial foraging decisions reflect spatial and temporal knowledge of resource distributions. Animal Cognition, 19, 387-403.

Jakes, A.F., Jones, P.F., Paige, L.C., Seidler, R.G. \& Huijser, M.P. (2018) A fence runs through it: a call for greater attention to the influence of fences on wildlife and ecosystems. Biological Conservation, 227, 310-318.

Jaramillo Díaz, P. \& Guèzou, A. (2011) CDF Checklist of Galapagos vascular plants. In Charles Darwin Foundation Galapagos Species Checklist (eds F. Bungartz, H. Herrera, P. Jaramillo, N. Tirado, G. Jiménez-Uzcátegui, D. Ruiz et al.). Charles Darwin Foundation, Puerto Ayora, Galapagos, Ecuador. darwinfoundation.org/en/ datazone/checklist [accessed 10 January 2019].

LaPoint, S., Balkenhol, N., Hale, J., Sadler, J. \& van der Ree, R. (2015) Ecological connectivity research in urban areas. Functional Ecology, 29, 868-878.
Laso, F.J., Benitez, F.L., Rivas-Torres, G., Sampedro, C. \& ArCe-NazArio, J. (2020) Land cover classification of complex agroecosystems in the non-protected highlands of the Galapagos Islands. Remote Sensing, 12, 65.

LeE, P.L.M., Luschi, P. \& Hays, G.C. (2007) Detecting female precise natal philopatry in green turtles using assignment methods. Molecular Ecology, 16, 61-74.

MacFarland, C.G., Villa, J. \& Toro, B. (1974) The Galapagos giant tortoises (Geochelone elephantopus) part II: conservation methods. Biological Conservation, 6, 198-212.

Mazerolle, M.J. (2015) AICcmodavg: Model Selection and Multimodel Inference Based on (Q)AIC(c). R package version 2.2-1. cran.r-project.org/web/packages/AICcmodavg/AICcmodavg.pdf [accessed June 2021].

McClure, M.L., Dickson, B.G. \& Nicholson, K.L. (2017) Modeling connectivity to identify current and future anthropogenic barriers to movement of large carnivores: a case study in the American Southwest. Ecology and Evolution, 7, 3762-3772.

McIvor, D.E. \& Conover, M.R. (1994) Impact of greater sandhill cranes foraging on corn and barley crops. Agriculture, Ecosystems and Environment, 49, 233-237.

McMullen, C.K. (1999) Flowering Plants of the Galapagos. Cornell University Press, Ithaca, USA.

Milchunas, D. \& Lauenroth, W. (1993) Quantitative effects of grazing on vegetation and soils over a global range of environments. Ecological Monographs, 63, 327-366.

Nieto-Claudin, A., Esperón, F., Blake, S. \& Deem, S. (2019) Antimicrobial resistance genes present in the fecal microbiota of free-living Galapagos tortoises (Chelonoides porteri). Zoonoses and Public Health, 66, 900-908.

Panzacchi, M., van Moorter, B., Strand, O., Saerens, M., KivimäKi, I., St. Clair, C.C. et al. (2016) Predicting the continuum between corridors and barriers to animal movements using step selection functions and randomized shortest paths. Journal of Animal Ecology, 85, 32-42.

Polansky, L., Kilian, W. \& Wittemyer, G. (2015) Elucidating the significance of spatial memory on movement decisions by African savannah elephants using state-space models. Proceedings of the Royal Society B: Biological Sciences, 282, 20143042.

Poulakakis, N., Edwards, D.L., Chiari, Y., Garrick, R.C., Russello, M.A., Benavides, E. et al. (2015) Description of a new Galapagos giant tortoise species (Chelonoidis; Testudines: Testudinidae) from Cerro Fatal on Santa Cruz Island. PLOS ONE, 10, e0138779.

QGIS Development Team (2016) QGIS Geographic Information System. Open Source Geospatial Foundation Project. qgis.osgeo.org [accessed 1 February 2021].

R Core Team (2020) R: A Language and Environment for Statistical Computing. R Foundation for Statistical Computing, Vienna, Austria. r-project.org/foundation [accessed 1 February 2021].

Rivas-Torres, G.F., Benítez, F.L., Rueda, D., Sevilla, C. \& Mena, C.F. (2018) A methodology for mapping native and invasive vegetation coverage in archipelagos: an example from the Galápagos Islands. Progress in Physical Geography, 42, 83-111.

Sampedro, C., Pizzitutti, F., Quiroga, D., Walsh, S.J. \& Mena, C.F. (2018) Food supply system dynamics in the Galapagos Islands: agriculture, livestock and imports. Renewable Agriculture and Food Systems, 35, 234-248.

Shackelford, G.E., Steward, P.R., German, R.N., Sait, S.M. \& Benton, T.G. (2015) Conservation planning in agricultural landscapes: hotspots of conflict between agriculture and nature. Diversity and Distributions, 21, 357-367.

SHAw, A.K. (2016) Drivers of animal migration and implications in changing environments. Evolutionary Ecology, 30, 991-1007. 
Songhurst, A., McCulloch, G. \& Coulson, T. (2016) Finding pathways to human-elephant coexistence: a risky business. Oryx, 50, 713-720.

Symonds, M.R.E. \& Moussalli, A. (2011) A brief guide to model selection, multimodel inference and model averaging in behavioural ecology using Akaike's information criterion. Behavioural Ecology and Sociobiology, 65, 13-21.

Trueman, M. \& D'Ozouville, N. (2010) Characterizing the Galapagos terrestrial climate in the face of global climate change. Galapagos Research, 67, 26-37.

Trueman, M., Hobbs, R.J. \& van Niel, K. (2013) Interdisciplinary historical vegetation mapping for ecological restoration in Galapagos. Landscape Ecology, 28, 519-532.

Tyrrell, P., Russell, S. \& Western, D. (2017) Seasonal movements of wildlife and livestock in a heterogenous pastoral landscape: implications for coexistence and community based conservation. Global Ecology and Conservation, 12, 59-72.
Venter, O., Sanderson, E.W., Magrach, A., Allan, J.R., Beher, J., Jones, K.R. et al. (2016) Sixteen years of change in the global terrestrial human footprint and implications for biodiversity conservation. Nature Communications, 7, 12558.

Watson, J., Trueman, M., Tufet, M., Henderson, S. \& Atrinson, R. (2010) Mapping terrestrial anthropogenic degradation on the inhabited islands of the Galapagos Archipelago. Oryx, 44, 79-82.

Winner, K., Noonan, M.J., Fleming, C.H., Olson, K.A., Mueller, T., Sheldon, D. \& Calabrese, J.M. (2018) Statistical inference for home range overlap. Methods in Ecology and Evolution, 9, 1679-1691.

Wikelski, M., Davidson, S. \& Kays, R. (2019) Movebank: Archive, Analysis and Sharing of Animal Movement Data. Max Planck Institute of Animal Behaviour, Radolfzell, Germany. movebank.org [accessed 1 July 2019].

Yackulic, C.B., Blake, S. \& Bastille-Rousseau, G. (2017) Benefits of the destinations, not costs of the journeys, shape partial migration patterns. Journal of Animal Ecology, 86, 972-982. 